Research Article

\title{
Evaluating the Rail-Based Multimodal Freight Transportation after HSR Entry in Yangtze River Delta Economics Zone
}

\author{
Junliang He $\mathbb{D}^{1,2}$ Minghui Wei, ${ }^{3}$ Hang Yu $\left(\mathbb{D},{ }^{2}\right.$ Jun Yuan, ${ }^{2}$ and Yanbing Chen ${ }^{4}$ \\ ${ }^{1}$ Engineering Research Center of Container Supply Chain Technology, Ministry of Education, Shanghai Maritime University, \\ Shanghai, China \\ ${ }^{2}$ China Institute of FTZ Supply Chain, Shanghai Maritime University, Shanghai, China \\ ${ }^{3}$ School of Economics and Management, Shanghai Maritime University, Shanghai, China \\ ${ }^{4}$ Freight Department, China Railway Shanghai Group Co., Ltd., Shanghai, China \\ Correspondence should be addressed to Hang Yu; yuhang@shmtu.edu.cn
}

Received 11 February 2021; Revised 24 February 2021; Accepted 28 February 2021; Published 10 March 2021

Academic Editor: Lu Zhen

Copyright (C) 2021 Junliang He et al. This is an open access article distributed under the Creative Commons Attribution License, which permits unrestricted use, distribution, and reproduction in any medium, provided the original work is properly cited.

\begin{abstract}
In recent years, China keeps working on restructuring the country's multimodal transport and highly develops the high-speed rail (HSR) infrastructure to improve transport efficiency. As the economic engine of China, the Yangtze River Delta region keeps leading the HSR development and the transporting modal transformation within the whole country. The fast development of HSR on the one hand highly improves passengers' travel efficiency and, on the other hand, releases the capacity of conventional rail infrastructures to support regional multimodal freight transport. This study applies a three-level AHP structure and constructs a comprehensive index to evaluate the development of a rail-based multimodal freight transport network including railway, railwater, and rail-road. The comprehensive index contains 14 quantitative and 8 qualitative indexes, covering the rail-based infrastructures, multimodal transport capability, freight transport performance, and transport sustainability. The comprehensive index is then applied to analyze the rail-based multimodal freight transport for the Yangtze River Delta region. The operational data of 59 freight stations and more than 200 railway links of the Yangtze River Delta were recorded. About 172 valid questionnaires were collected to score the qualitative indexes, and all the quantitative indexes are scored based on the real-life freight data. The results reveal the impacts of HSR development on rail freight transportation and show that Zhejiang has led rail freight transportation while Shanghai mainly leads the waterway freight transportation. Meanwhile, Anhui performs very well on roadrail transportation and Jiangsu has made a great improvement on water-rail transportation.
\end{abstract}

\section{Introduction}

In the past five years, China invested more than 80 billion yuan each year in the construction of high-speed rail (HSR). By the end of 2019, the total revenue length of HSR in China had reached $35,000 \mathrm{~km}$ and ranked first place in the world. HSR commanded a share of $64.4 \%$ in the total rail passengers by the end of 2019. At the same time, the development of HSR and the shift away from traditional passenger rail services have released the capacity of conventional rail infrastructures to support freight transport including multimodal freight transport. In China State Council's Three-Year
Action Plan for Promoting Transport Restructuring (20182020) (The Action Plan) released in 2018, rail-based freight transport was given unprecedented attention and improved the bulk freight volume via rail and water was set as the priority goal of this action plan.

As the economic engine of China, the Yangtze River Delta region including three provinces, Jiangsu, Zhejiang, and Anhui, and one province-level city (municipality), Shanghai, accounts for about $1 / 4$ of the national GDP with only $2.1 \%$ of the nation's land area. Within this area, both the traditional railway and HSR are highly developed and lead the whole country. The total revenue length of HSR in 
Yangtze River Delta has already reached 5,000 kilometers, and four main HSR lines go through in this region and join in Shanghai, as shown in Figure 1. The Jinghu, Hukun, and Yanjiang HSR lines all start from Shanghai and link through several main cities in the Yangtze River Delta. Meanwhile, the Yanhai HSR is also being designed to link the main coastal cities of the Yangtze River Delta. As a result, the HSR had already been the main choice for rail travelers, and the released capacity of conventional rail infrastructures is transferred for the use of freight transportation in the Yangtze River Delta. At the same time, with the implementation of The Action Plan since 2018, rail-based multimodal transport has been quickly developed. Such revolutionary changes have not been documented and examined by the existing studies. Even in other countries where the HSR network has been developed, the impact of HSR on freight transportation, particularly its impact on rail-based multimodal transportation, has been largely ignored.

Therefore, this study aims to document the current status of the development of rail-based multimodal freight transportation in the Yangtze River Delta due to the capacity freed up by the launch of HSR. In addition, we construct an AHP-based performance index comprising qualitative and quantitative indicators to evaluate the development of the rail-based multimodal freight transportation network including rail-rail, rail-water, and rail-road. This study will inform relevant stakeholders, particularly the policymakers to recognize the current performance of the multimodal transportation in each province in the Yangtze River Delta, which will assist them to design a long-term transport master plan for a multimodal freight transport network in the Yangtze Delta as HSR construction continues in this region.

\section{Background}

The study targets the multimodal freight transport network among three provinces (Zhejiang, Jiangsu, and Anhui) and one municipality (Shanghai) in The Yangtze River Delta region. Based on the freight transport data in 2018 and 2019, the study chooses 59 rail stations (the chosen stations accounting for $80 \%$ of the whole rail transport traffic in 2018 in Yangtze River Delta) as the key nodes to form the evaluation network. The evaluated network includes not only cities from the arterial rail lines but also main cities from the branch lines. This sampling network thus contains 31 cities with HSR stations and more than 200 railway links as shown in Figure 2. In order to capture the booming water-based transportation performance [1] considering sustainable requirements as mentioned in Tan and $\mathrm{He}$ [2] and $\mathrm{He}$ et al. [3], eight ports with railway freight stations are also evaluated in this research.

All the 59 evaluated rail stations are located in the conventional rail freight network within the Yangtze River Delta. As every city in the Yangtze River Delta has already been linked by the HSR, all the evaluated freight stations are likely affected by the HSR development. To have a closer look at the effects of the HSR development, this study separates the 59 stations into 29 arterial stations and 30 branch stations. All the 29 arterial stations are located along the national eight vertical and eight horizontal HSR lines. The distribution of the 59 stations can be found in Table 1.

The freight and container traffic at these stations in 2019 for the three provinces and Shanghai is reported in Table 2. It can be seen that arterial stations recorded the largest increase, particularly in Jiangsu province. However, the freight traffic at the stations in Shanghai slightly dropped from 2018 to 2019. Freight traffic at the arterial stations in Anhui also recorded a slight decrease in 2019.

The freight multimodal network in the Yangtze River Delta is well developed. For the rail-road transport, Anhui outperformed the other three provinces because of the highly developed conventional railway freight network (see Figure 3). Meanwhile, rail-road is rarely used to distribute freight and containers in Shanghai.

Figures 4 and 5 present the market shares of water-based multimodal transportation modes at eight ports in the Yangtze River Delta area in 2019. It can be seen that railwater mode accounted for a very small share in all the provinces except for Anhui. The region has very developed water transportation systems, and most of these ports mainly focus on water-water freight transportation. For container transportation, road-based transport is still the first choice by customers for most areas in the Yangtze River Delta. There is much room to promote the rail-water model in this region.

\section{Literature Review}

China's first HSR was launched between Beijing and Tianjin. The first long-haul HSR was the HSR put into use in 2009. A decade later, China has become a world leader in HSR construction [4]. The total length of China's HSR will reach $38,000 \mathrm{~km}$ by 2025 and 45,000 by 2030 . The impact of HSR on various aspects of the economy has been well studied (for a good survey, see [5]). After more than ten years' construction, the entry of HSR has made a significant impact on the regional development in China. Chen and Haynes [6] propose a conceptual framework to assess the impact of HSR on regional economic disparity. They confirm that the regional economic disparity has been decreased since the development of HSR in China. Zhang et al. [7] studied the impacts of HSR development on regional equity in China and found that the launch of HSR is positively associated with provincial equity. Long et al. [8] report that the entry of HSR accelerates urban expansion and benefit more for the underdeveloped central and western cities in China. Liang et al. [9] hold a similar view. However, Li et al. [10] found that positive impacts are shown to be greater for metropolis than small cities, which implies that HSR also contributes significantly to the economic development of the wealthy eastern region [11] including the Yangtze River Delta Region and Pearl River Delta Region [12]. Despite these positive impacts, Sun and Mansury [13] pointed out that HSR may also contribute to the widening gap between developed and underdeveloped regions. Overall, it seems that the benefits brought about by HSR are significant and unambiguous. However, up to today, there is a 


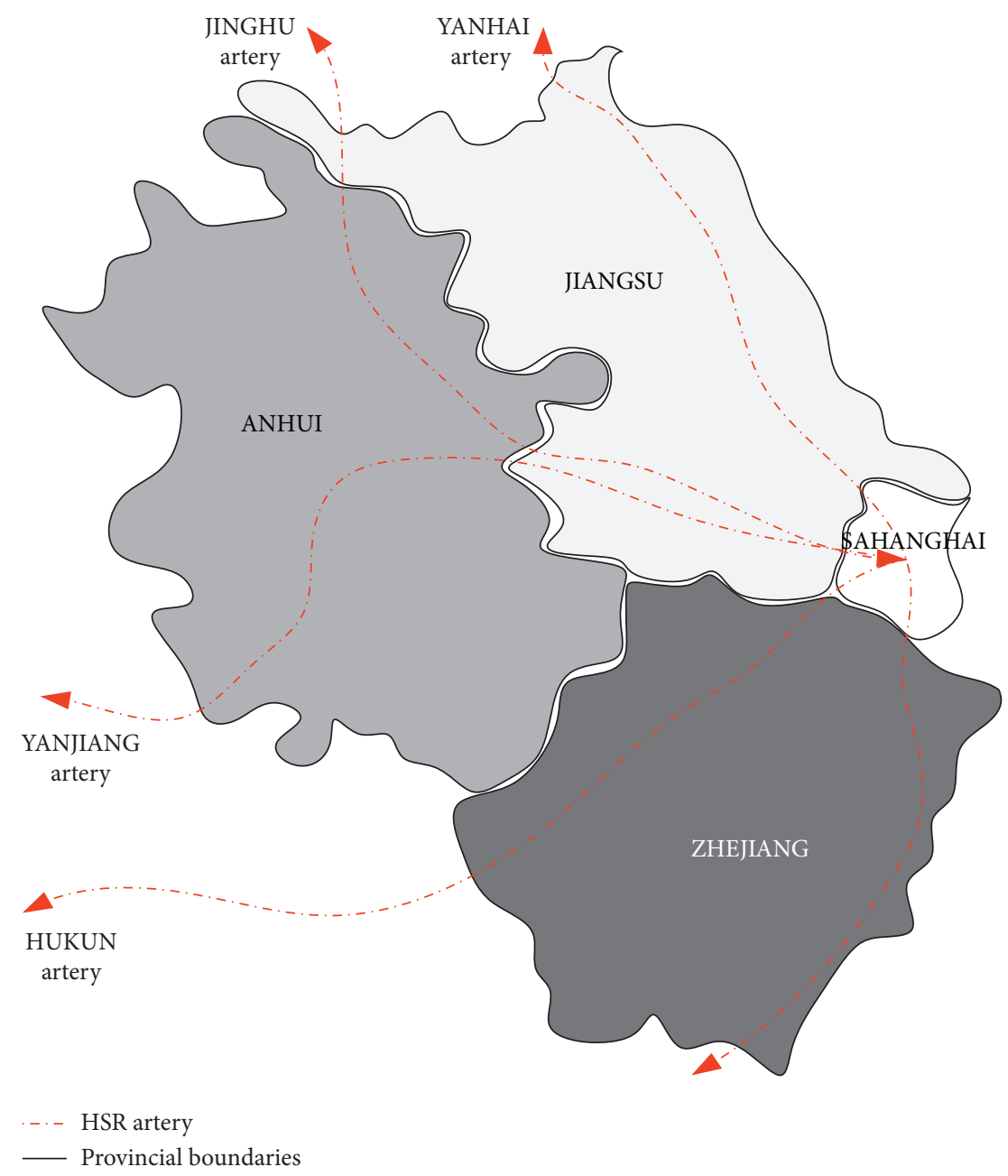

Figure 1: Major HSR lines in Yangtze River Delta.

lack of systematic and comprehensive approaches to quantify the impacts of HSR on the economy as a whole or one particular industry or sector.

International experiences have proven that the HSR development has direct and indirect effects on regional development and creates opportunities to reconstruct the urban system, in both spatial and economic terms [14]. Cascetta et al. [15] evaluated the impact of HSR on economic growth, transport accessibility, and regional quality in Italy ten years after the HSR operation and found significant links between these variables. With the development of the HSR network, the impacts of HSR are also widely received in China. Chen [16] assessed the economic and environmental impact of HSR development from the regional development perspective with proofs where the effects of HSR on the increase of the land value, housing value, and tourism demand are real and significant. From the tourism perspective, Weng et al. [17] revealed that the HSR has become the main choice for short- and medium-range travel distances for tourists. The domestic tourism market improvement due to the presence of HSR is particularly for small- and mediumsized cities. Chen and Haynes [18] and Yang and Li [19] both found that the development of HSR can attract more international tourism and boost inbound tourism.
Furthermore, the development of HSR poses a big challenge to traditional transport markets especially the air transport sector [5, 20]. Zhang et al. [21] and Zhang et al. [22] demonstrated that the negative impacts on air transport are strong with the entry of HSR, particularly for major airline routes. The development of HSR has forced airline companies to reduce their prices and improve services, particularly punctuality to retain existing and attract new passengers $[23,24]$. Its threat to low-cost carriers is more prominent due to the close substitution of the two [25]. Meanwhile, the opening of HSR has gradually reshaped the regional freight transport structure. With the entry of HSR, rail-based freight transport becomes more competitive in the regional multimodal transport systems. It is acknowledged that the HSR-based freight transport system is more efficient and cost-effective [26]. However, the development of the HSR-based freight transport network requires a significant investment which is not an easy decision for many governments [27].

Therefore, the conventional railway infrastructure continues to play an important role in rail-based freight transportation. Li et al. [28] indicate that there has been a significant reduction of conventional train services because of the entry of HSR, which makes room for freight 


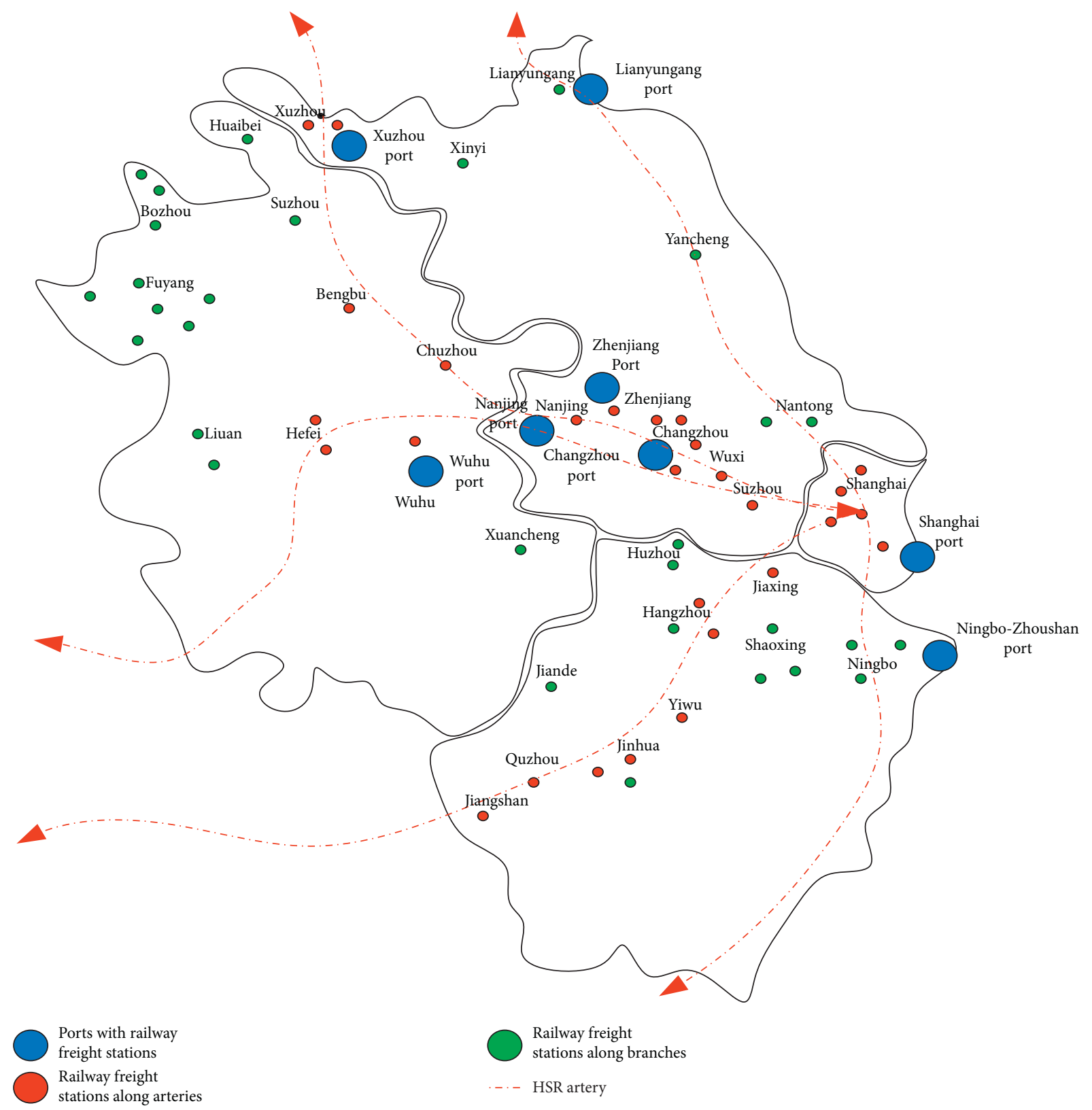

FIgURE 2: The rail-based multimodal freight transport network in Yangtze River Delta.

TABLE 1: The distribution of evaluated rail freight stations*.

\begin{tabular}{lcccc}
\hline & Shanghai & Zhejiang & Jiangsu & Anhui \\
\hline Arterial stations & 6 & 8 & 10 & 5 \\
Branch stations & 0 & 11 & 5 & 14 \\
\hline
\end{tabular}

*Shanghai is the key node for several HSR arteries; thus, all the stations in Shanghai are classified as arterial stations.

transportation using the traditional train lines. This represents a spillover effect of HSR development. However, in the existing literature on HSR impacts, little has been said about the promotion effect of HSR on the development of railbased freight transportation. This research aims to fill this literature gap by designing a comprehensive performance index to measure the development of the rail-based freight multimodal transport system, including rail-rail, rail-road, and rail-water in the Yangtze River Delta.

\section{Methodology}

This study applies a three-level AHP structure and constructs a comprehensive index to evaluate the development of a rail-based multimodal freight transport network. This AHP-based performance index contains 14 quantitative and 8 qualitative indicators, covering the rail-based infrastructures, multimodal transport capability, freight transport performance, and transport sustainability. The index has three levels with the first level including regional distribution network, multimodal transport capacity, and transport operational performance sustainability as shown in Table 3. 
TABle 2: The 2019 traffic of the evaluated freight stations in Yangtze River Delta.

\begin{tabular}{|c|c|c|c|c|c|c|}
\hline & & Yangtze River Delta & Shanghai & Zhejiang & Jiangsu & Anhui \\
\hline \multirow{6}{*}{ Freight traffic (000'tonnes) } & Arterial stations & 44478.29 & 6936.2 & 15687.36 & 19332.22 & 13717.36 \\
\hline & Year on year & $20.91 \%$ & $-1.39 \%$ & $19.81 \%$ & $38.13 \%$ & $-0.20 \%$ \\
\hline & Branch stations & 40050.05 & - & 14231.31 & 2668.31 & 11955.57 \\
\hline & Year on year & $14.99 \%$ & - & $24.63 \%$ & $-5.06 \%$ & $25.62 \%$ \\
\hline & Total & 84528.34 & 6936.2 & 29918.67 & 22000.54 & 25672.93 \\
\hline & Year on year & $18.03 \%$ & $-1.39 \%$ & $22.05 \%$ & $30.91 \%$ & $10.36 \%$ \\
\hline \multirow{6}{*}{ Container traffic (000'TEU) } & Arterial stations & 1369.66 & 322.57 & 482.99 & 531.37 & 138.32 \\
\hline & Year on year & $47.94 \%$ & $22.25 \%$ & $37.75 \%$ & $90.50 \%$ & $90.21 \%$ \\
\hline & Branch stations & 515.46 & - & 339.75 & 34.58 & 35.52 \\
\hline & Year on year & $37.34 \%$ & - & $27.45 \%$ & $-3.76 \%$ & $9.28 \%$ \\
\hline & Total & 1885.11 & 322.57 & 822.75 & 565.95 & 173.84 \\
\hline & Year on year & $44.88 \%$ & $22.25 \%$ & $33.30 \%$ & $79.75 \%$ & $65.21 \%$ \\
\hline
\end{tabular}

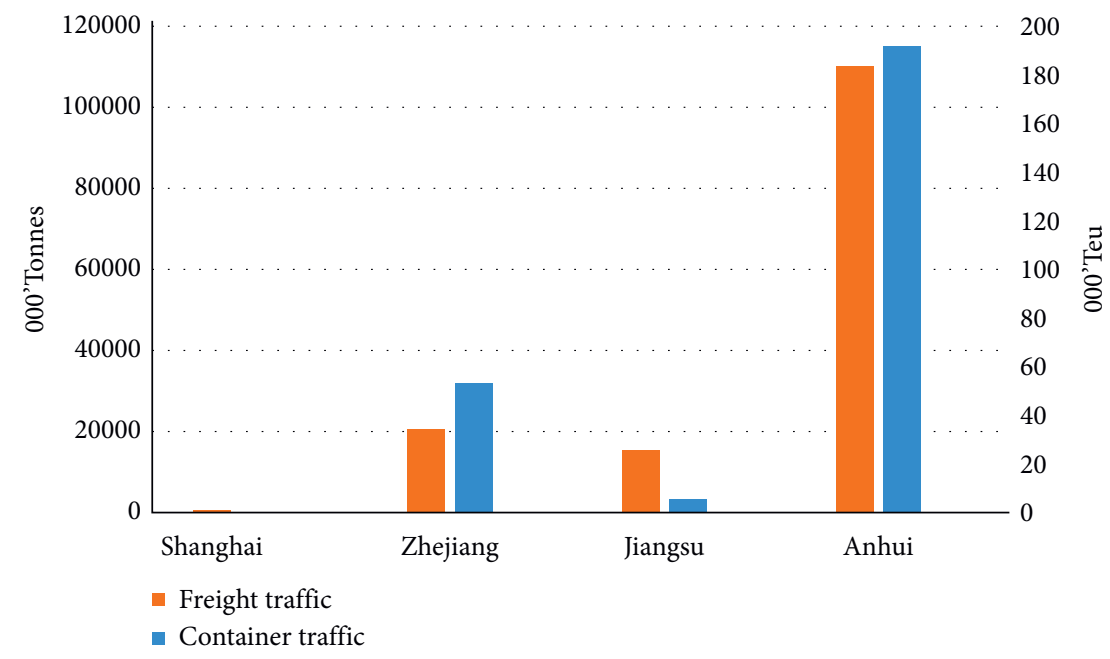

FIGURE 3: The rail-road freight transport traffic.

All the indicators are selected by the brainstorming meeting with experts experienced with rail-based transport from the Yangtze River Delta region. Meanwhile, a questionnaire was designed to collect transport experts' opinions on the qualitative indicators. The survey includes two parts: the first part is to compare the significance between indicators as shown in Table 4; the second part is to score the qualitative indicators (C11, C12, C13, C21, C22, D31) based on the questions in Table 5. The questionnaires were sent to more than 200 logistics companies that had multimodal freight transport experience and 172 valid questionnaires were collected. Meanwhile, all the quantitative indicators are scored based on real-life freight data.

The single-level ordering method is used to score the three-level index system. To validate the index system's consistency, this study uses the ANC (Asymptotic Normalization Coefficient) method to calculate the maximal eigenvalue of the AHP judgment matrix $\mathbf{B}$ and its corresponding eigenvector. The judgment matrix $\mathbf{B}$ is defined as

$$
\mathbf{B}=\left[\begin{array}{ccc}
b_{11} & \cdots & b_{1 j} \\
\vdots & \ddots & \vdots \\
b_{i 1} & \cdots & b_{i j}
\end{array}\right],
$$

where $b_{i j}$ represents the importance of index $i$ to index $j$ at a certain level. The matrix $\mathbf{B}$ is obtained by the expert scoring method. Each column of the matrix is then normalized, with the formula as follows:

$$
\bar{b}_{i j}=\frac{b_{i j}}{\sum b_{i j}}, \quad i, j=1,2, \ldots, n .
$$

The matrix after column normalization is added by row to $\bar{W}_{i}=\sum \bar{b}_{i j}$. Then, the vector $\bar{W}=\left[\bar{W}_{1}, \bar{W}_{2}, \ldots, \bar{W}_{n}\right]^{T}$ can be normalized as

$$
W_{i}=\frac{\bar{W}_{i}}{\sum \bar{W}_{j}} \quad, i, j=1,2, \ldots, n .
$$

The eigenvector can be expressed as $W=\left[W_{1}, W_{2}, \ldots, W_{N}\right]^{T}$, so that the maximal eigenvalue $\lambda_{\max }$ of the judgment matrix can be calculated through

$$
\lambda_{\max }=\sum_{i=1}^{n} \frac{(B W)_{i}}{n W_{i}} .
$$

The solution of the maximal eigenvalue $\lambda_{\max }$ is the basis of the consistency verification, which is carried out by the following formulas: 

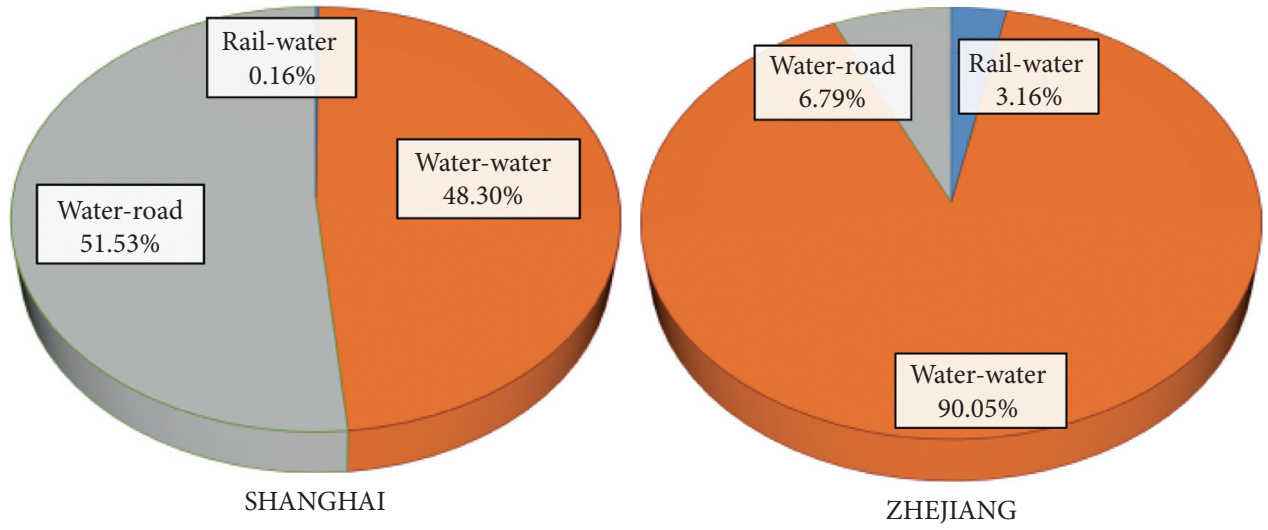

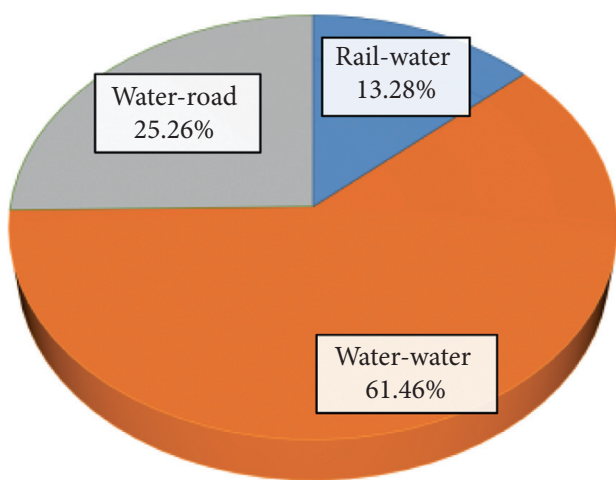

JIANGSU

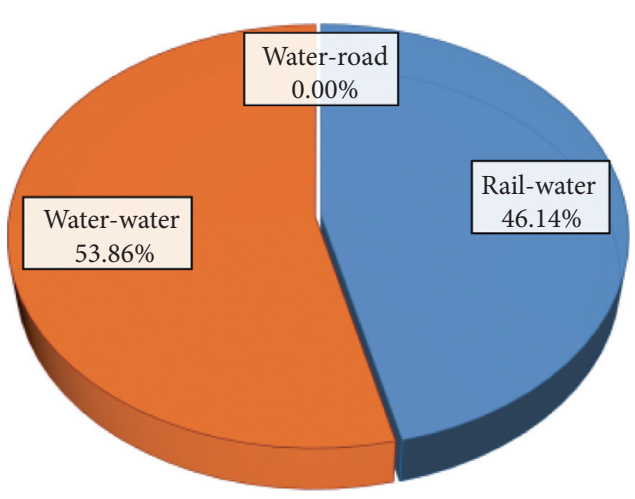

ANHUI

Figure 4: The water-based freight traffic in Yangtze River Delta.

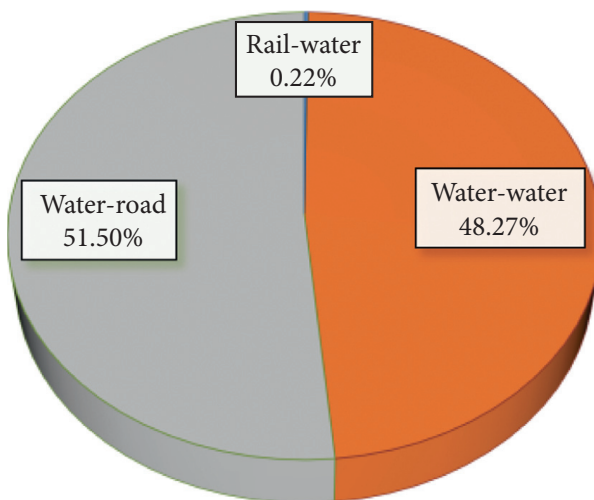

SHANGHAI

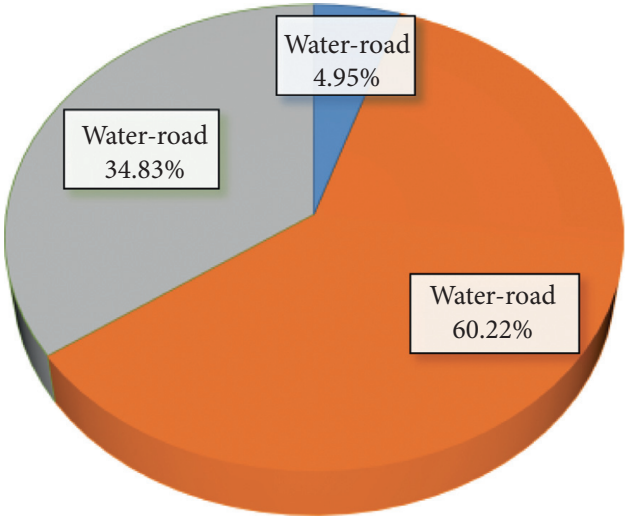

JIANGSU

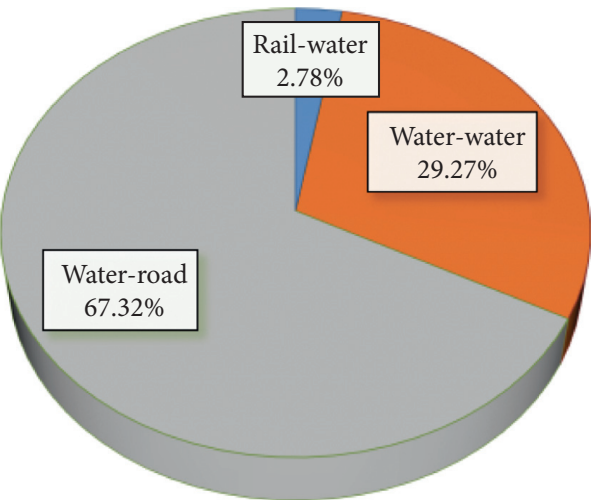

ZHEJIANG

No container traffic recorded in the evaluated ports in Anhui

Figure 5: The water-based container traffic in Yangtze River Delta. 
TABle 3: The framework of the AHP-based index.

\begin{tabular}{|c|c|c|}
\hline First level & Second level & Third level \\
\hline Regional distribution network (A) & Multimodal transport infrastructure (A1) & $\begin{array}{c}\text { Public rail stations and railway links (A11) } \\
\text { Exclusive railway (A12) } \\
\text { Port shoreline (A13) } \\
\text { Highway density (A14) } \\
\text { Public rail freight volume (A21) } \\
\text { Exclusive rail freight volume (A22) } \\
\text { Port throughput (A23) } \\
\text { Highway freight volume (A24) }\end{array}$ \\
\hline Multimodal transport capability (B) & $\begin{array}{c}\text { Rail-water transport (B1) } \\
\text { Water-water transport (B2) } \\
\text { Road-water transport (B3) } \\
\text { Road-rail transport (B4) } \\
\end{array}$ & $\begin{array}{l}\text { Rail-water transport volume (B11) } \\
\text { Water-water transport volume (B21) } \\
\text { Road-water transport volume (B31) } \\
\text { Road-rail transport volume (B41) }\end{array}$ \\
\hline Transport operational performance (C) & $\begin{array}{c}\text { Technical improvement (C2) } \\
\text { Safety control (C3) }\end{array}$ & $\begin{array}{c}\text { Multimodal transport delay }(\mathrm{C} 11) \\
\text { Multimodal transfer efficiency }(\mathrm{C} 12) \\
\text { Revenue of multimodal transport (C13) } \\
\text { Informatization (C21) } \\
\text { Availability (C22) } \\
\text { Ratio of accidents (C31) } \\
\text { Average compensation for every accident (C32) }\end{array}$ \\
\hline Sustainability (D) & $\begin{array}{l}\text { Economic (D1) } \\
\text { Environment (D2) } \\
\text { Social (D3) }\end{array}$ & $\begin{array}{l}\text { Improvement of market share (D11) } \\
\text { Unit energy consumption (D21) } \\
\text { Policy implication (D31) }\end{array}$ \\
\hline
\end{tabular}

TABle 4: The description of the comparison significance between indicators is introduced as Mu and Pereyra-Rojas [29].

\begin{tabular}{lc}
\hline Significance $(i)$ & Description \\
\hline 9 & Compared with $j$, indicator $i$ is extremely important \\
7 & Compared with $j$, indicator $i$ is very strongly more important \\
5 & Compared with $j$, indicator $i$ is strongly more important \\
3 & Compared with $j$, indicator $i$ is moderately more important \\
1 & Compared with $j$, indicator $i$ is equally important \\
$2,4,6,8$ & The intermediate values between the two adjacent judgments, used when a compromise is needed \\
\hline
\end{tabular}

$$
\mathrm{CI}=\frac{\lambda_{\max }-n}{n-1} \times \frac{1}{\mathrm{RI}}<0.1
$$

CI represents the consistency verification value. The value of RI depends on the dimensions of the index. Dimensions 1 to 4 are $0,0,0.58$, and 0.90 , respectively.

If the verification results of $\mathrm{CI}$ meet the above conditions, the index system meets the consistency requirements. The eigenvector $W=\left[W_{1}, W_{2}, \ldots, W_{N}\right]^{T}$ can be considered as the evaluation index weight that represents the importance ranking of the index to its superior index. The description of the significance comparison between indicators can be found in Table 4 . Using equations (1)-(4), the index scores for qualitative indicators (C11, C12, C13, C21, C22, D31) can be calculated. For quantitative indicators, calculations are made using real-life data. The details of the raw data for every indicator can be found in Table 5. It is necessary to normalize the data of different dimensions and then calculate the corresponding scores. By doing so, we can obtain different scores of the third-level indicators. The second-level indicators' scores are obtained by the weighted sum of the corresponding third-level indicators' weights and scores. The first-level indicators' scores are obtained by the weighted sum of the second-level indicators' weights and scores. The scores of different indicators can be applied to analyze the development of multimodal transportation within the evaluated network.

\section{Results and Discussion}

5.1. The Impact of HSR on Railway Transportation in Yangtze River Delta. To reveal the different features of HSR impacts on the arterial and branch stations, Figures 6-9 compare the transport traffic (both freight and container traffic) in 2019 with the data in 2015 (the vertical axes in these figures indicate the traffic data in 2019 minus the corresponding data in 2015).

Compared with 2015, the rail freight traffic experienced a drop in 2019, probably because, in recent years, China has taken actions to restrict the consumption of coals to protect the environment, which has decreased the demand for bulk transportation. It is also noticed that the drop took place at branch stations. In contrast, the arterial stations recorded a substantial increase in traffic, largely due to the capacity release as a result of the HSR development. It seems that freight traffic has become more concentrated in the arterial stations. Our interviewers note that with the development of the HSR network, more passengers ( $80 \%$ of the total railway 
TABLE 5: The description of original data for every indicator.

Indicators

Public rail stations and railway links (A11)

Exclusive railway (A12)

Port shoreline (A13)

Highway density (A14)

Public rail freight volume (A21)

Exclusive rail freight volume (A22)

Port throughput (A23)

Highway freight volume (A24)

Rail-water transport volume (B11)

Water-water transport volume (B21)

Road-water transport volume (B31)

Road-rail transport volume (B41)

Multimodal transport delay* (C11)

Multimodal transfer efficiency (C12) *

Revenue of multimodal transport

$(\mathrm{C} 13)^{*}$

Informatization $(\mathrm{C} 21)^{*}$

Availability (C22) *

Ratio of accidents (C31)

Average compensation for every

accident (C32)

Improvement of market share (D11)

Unit energy consumption (D21)

Policy implication (D31)*
Original data description

The number of railway stations and links for public freight transport in the evaluated network

The number of railway links of transporting freight for exclusive companies in the evaluated network

The length of the berthing line [30] for the evaluated ports

The highway density which equals the total length of a highway divided by the acreage of the area for the evaluated regions (Shanghai, Zhejiang, Jiangsu, Anhui)

The corresponding freight volume of A11 to A14 in 2019

The multimodal transport volume in 2019

How is the performance of multimodal transport? Do you satisfied with the service of the multimodal transport considering the possible delay?

How is the transferring efficiency in the multimodal stations or terminals?

Will you choose multimodal transport instead of your former transport choice? Is the cost of multimodal transport competitive?

How about the operations system of multimodal transport when you try to use it?

Is it convenient for you to get the service for multimodal transport?

No railway freight accident recorded in 2019 for the evaluated stations and links

The freight volume improvement (2019 compared with 2018) for multimodal transport in the evaluated network

The variation of energy consumption for unit freight transport (total consumption divide total freight volume)

How about the impacts of governmental policy implication for multimodal transport?

*The target scores for the qualitative indicators are based on the answers to the following questions by invited experts from 0 to 100 .

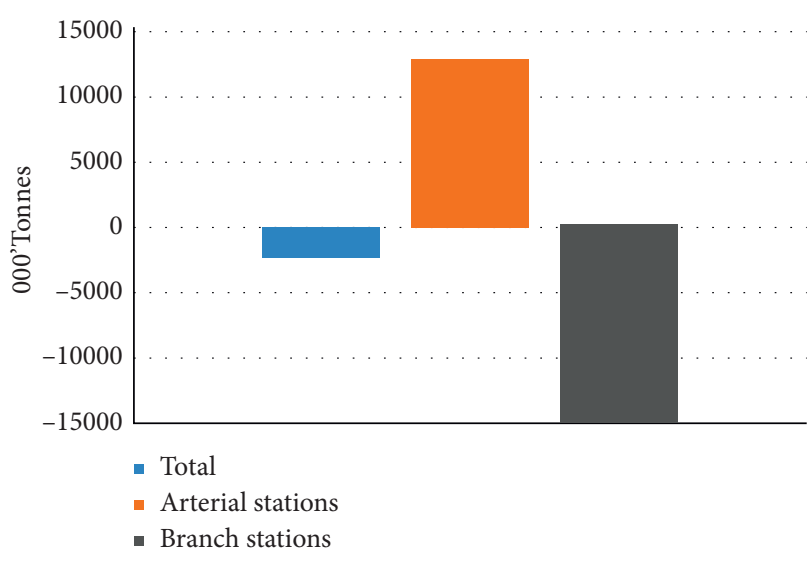

Figure 6: Freight traffic comparison between 2019 and 2015.

passengers in 2019) chose HSR instead of the conventional railway services especially those along the arterial stations. As a result, the conventional railway infrastructures were released for handling freight, which can explain the rise in freight traffic at arterial stations. The rise in container traffic is not surprising as, in recent years, incentive policies such as those noted in The Action Plan have been implemented to promote containerization transportation.

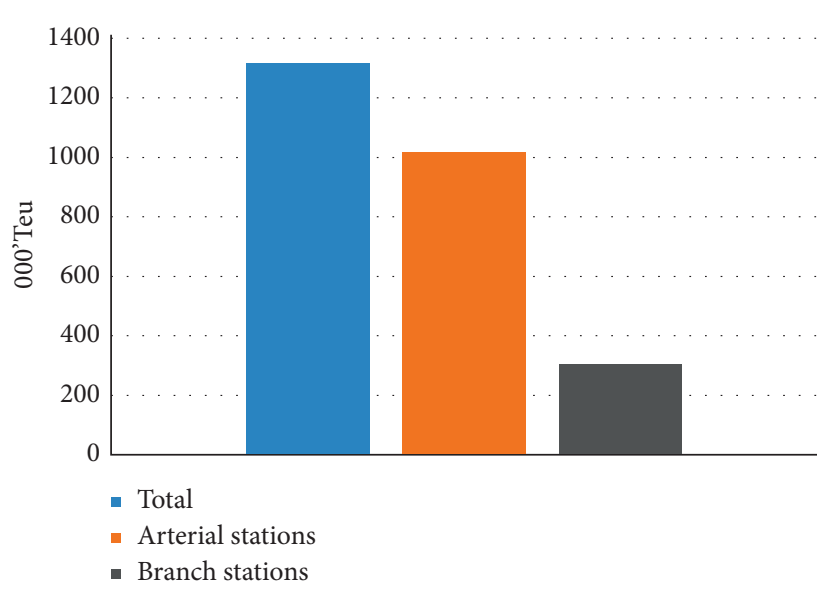

Figure 7: Container traffic comparison between 2019 and 2015.

Figures 8 and 9 further report the changes in freight and container traffic in these two years for Shanghai and three provinces. The same pattern can be observed for each province, suggesting that HSR has promoted the freight traffic at arterial stations. With the impacts of HSR development, the freight transport for arterial stations has been shown with a better opportunity to lead the rail-based freight transport. The results guide policymakers on the one hand focus on optimizing the conventional rail infrastructures to 


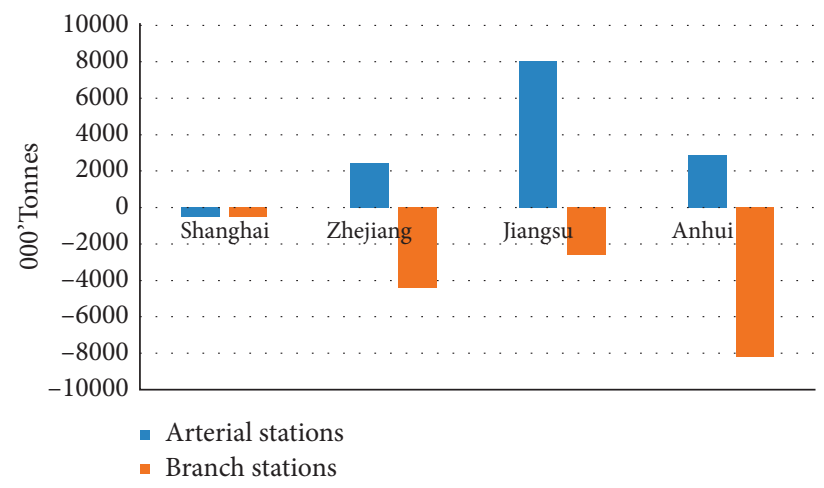

Figure 8: Freight traffic comparison between 2019 and 2015.

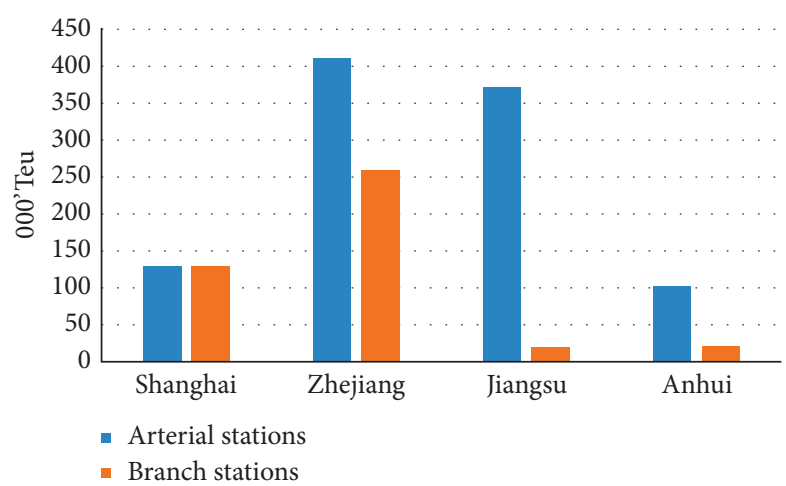

FIGURE 9: Container traffic comparison between 2019 and 2015.

support rail-based freight transport for arterial stations and, on the other hand, release more incentives for promoting rail-based traffic for branch stations.

5.2. The Current Status of the Rail-Based Multimodal Transport in Yangtze River Delta. The evaluation index weights based on Section 4 are shown in Table 6. The index scores for each indicator and province are reported in $\mathrm{Ta}-$ ble 7 . Zhejiang leads other provinces with the highest overall score, 92.36, followed by Jiangsu, 89.97; Anhui, 88.32; and Shanghai, 88.05.

The scores of the first-level indicators are shown in Figure 10. It can be seen that Zhejiang scores the highest in multimodal transport capacity, transport operational performance, and sustainability, while Anhui has the highest score in the regional distribution network.

The evaluation results of the regional distribution network are shown in Figure 11. Shanghai's transport infrastructures are relatively strong, especially in terms of highway density, port shoreline, and port throughput as shown in Table 7 . However, their weights are small based on expert scoring which makes Shanghai lag behind in the railbased infrastructure and operations. In contrast, Anhui is more developed in exclusive railway and highway freight volume, public rail station, and exclusive railway links, whose weights are relatively higher. As a result, Anhui has the best multimodal transport operations. Meanwhile,
Zhejiang has a balanced development in public rail freight volume, port throughput, and its regional distribution network. In terms of multimodal transport capability in Figure 12, Zhejiang and Jiangsu have a better overall performance, and they are well developed in rail-water transport. For Shanghai, water-based transport including waterwater transport and road-water transport has developed more prominently, while Anhui has the best road-rail transport performance.

The evaluation results of the transport operational performance can be found in Figure 13. The research has investigated the main multimodal transport market in the Yangtze River Delta. The results show that Zhejiang received relatively higher scores for transport performance and technical improvement. Shanghai and Jiangsu do not lag too far behind in these two indicators because the development of technical improvement and transport performance is well developed in the Yangtze River Delta region. There was no railway freight accident recorded in 2019 and all provinces received 100 points. However, the technical improvement and transport performance of Anhui received relatively lower points, implying that there is room for improvement for the indicators of transport delay, transfer efficiency, revenue, informatization, and availability as shown in Table 7.

In terms of sustainability, the scores can be seen in Figure 14. Shanghai is highly restricted by the strong waterbased transport and market, which have affected the 
TABLE 6: The evaluation indicators weight.

\begin{tabular}{|c|c|c|}
\hline First level & Second level & Third level \\
\hline \multirow{8}{*}{$0.2139(\mathrm{~A})$} & \multirow{5}{*}{$0.4220(\mathrm{~A} 1)$} & 0.5561 (A11) \\
\hline & & $0.2664(\mathrm{~A} 12)$ \\
\hline & & $0.1150(\mathrm{~A} 13)$ \\
\hline & & $0.0626(\mathrm{~A} 14)$ \\
\hline & & $0.5438(\mathrm{~A} 21)$ \\
\hline & \multirow{3}{*}{$0.5780(\mathrm{~A} 2)$} & $0.2302(\mathrm{~A} 22)$ \\
\hline & & 0.1367 (A23) \\
\hline & & $0.0894(\mathrm{~A} 24)$ \\
\hline \multirow{4}{*}{0.1659 (B) } & $0.5314(\mathrm{~B} 1)$ & $1.0000(\mathrm{~B} 11)$ \\
\hline & $0.1640(\mathrm{~B} 2)$ & $1.0000(\mathrm{~B} 21)$ \\
\hline & $0.1244(\mathrm{~B} 3)$ & $1.0000(\mathrm{~B} 22)$ \\
\hline & $0.1802(\mathrm{~B} 4)$ & $1.0000(\mathrm{~B} 23)$ \\
\hline \multirow{7}{*}{$0.3972(\mathrm{C})$} & \multirow{3}{*}{$0.4390(\mathrm{C} 1)$} & $0.4164(\mathrm{C} 11)$ \\
\hline & & 0.1867 (C12) \\
\hline & & $0.3969(\mathrm{C} 13)$ \\
\hline & \multirow{2}{*}{$0.2099(\mathrm{C} 2)$} & $0.5327(\mathrm{C} 21)$ \\
\hline & & $0.4673(\mathrm{C} 22)$ \\
\hline & \multirow{2}{*}{$0.3511(\mathrm{C} 3)$} & $0.4113(\mathrm{C} 31)$ \\
\hline & & $0.5887(\mathrm{C} 32)$ \\
\hline \multirow{3}{*}{$0.2230(\mathrm{D})$} & 0.3485 (D1) & $1.0000(\mathrm{D} 11)$ \\
\hline & $0.3746(\mathrm{D} 2)$ & $1.0000(\mathrm{D} 21)$ \\
\hline & $0.2769(\mathrm{D} 3)$ & $1.0000(\mathrm{D} 31)$ \\
\hline
\end{tabular}

TABLE 7: Index scores of the third-level indicators.

\begin{tabular}{|c|c|c|c|c|}
\hline The indicators of the third-level & Shanghai & Zhejiang & Jiangsu & Anhui \\
\hline Public rail stations and railway links (A11) & 82.23 & 87.00 & 88.55 & 94.23 \\
\hline Exclusive railway (A12) & 84.09 & 86.13 & 85.68 & 96.09 \\
\hline Port shoreline (A13) & 93.77 & 85.90 & 90.56 & 81.77 \\
\hline Highway density (A14) & 96.33 & 85.57 & 85.77 & 84.33 \\
\hline Public rail freight volume (A21) & 81.71 & 93.71 & 87.92 & 88.65 \\
\hline Exclusive rail freight volume (A22) & 84.09 & 87.19 & 84.63 & 96.09 \\
\hline Port throughput (A23) & 92.88 & 91.89 & 86.36 & 80.88 \\
\hline Highway freight volume (A24) & 81.24 & 88.12 & 89.39 & 93.24 \\
\hline Rail-water transport volume (B11) & 82.67 & 92.76 & 94.28 & 82.28 \\
\hline Water-water transport volume (B21) & 92.64 & 92.45 & 86.27 & 80.64 \\
\hline Road-water transport volume (B31) & 94.64 & 89.01 & 85.72 & 82.64 \\
\hline Road-rail transport volume (B41) & 83.73 & 87.49 & 85.06 & 95.73 \\
\hline Multimodal transport delay (C11) & 90.26 & 93.03 & 87.67 & 81.03 \\
\hline Multimodal transfer efficiency (C12) & 93.72 & 89.97 & 86.6 & 81.72 \\
\hline Revenue of multimodal transport (C13) & 86.57 & 95.04 & 87.35 & 83.04 \\
\hline Informatization (C21) & 88.18 & 94.04 & 87.75 & 82.04 \\
\hline Availability (C22) & 93.43 & 92.63 & 84.52 & 81.43 \\
\hline Ratio of accidents $(\mathrm{C} 31)^{*}$ & 100.00 & 100.00 & 100.00 & 100.00 \\
\hline Average compensation for every accident $(\mathrm{C} 32)^{*}$ & 100.00 & 100.00 & 100.00 & 100.00 \\
\hline Improvement of market share (D11) & 84.50 & 84.87 & 86.14 & 96.50 \\
\hline Unit energy consumption (D21) & 81.36 & 91.47 & 93.36 & 85.80 \\
\hline Policy implication (D31) & 85.85 & 95.02 & 88.11 & 83.02 \\
\hline
\end{tabular}

* As no railway freight accident is recorded in 2019 for the evaluated stations and links, the scores for C31 and C32 are 100.

development of railway freight transport, so the score is significantly lower. Meanwhile, the governmental policies seem too weak to promote the transformation of Shanghai's transport structure. In contrast, the governmental policies in Zhejiang are more active to stimulate rail-based transport.
Considering the environmental impacts, Jiangsu has the best performance with less road-based transport and more green modals. Meanwhile, Anhui is developing rapidly in the railbased multimodal transport based on the well-developed rail infrastructures. 


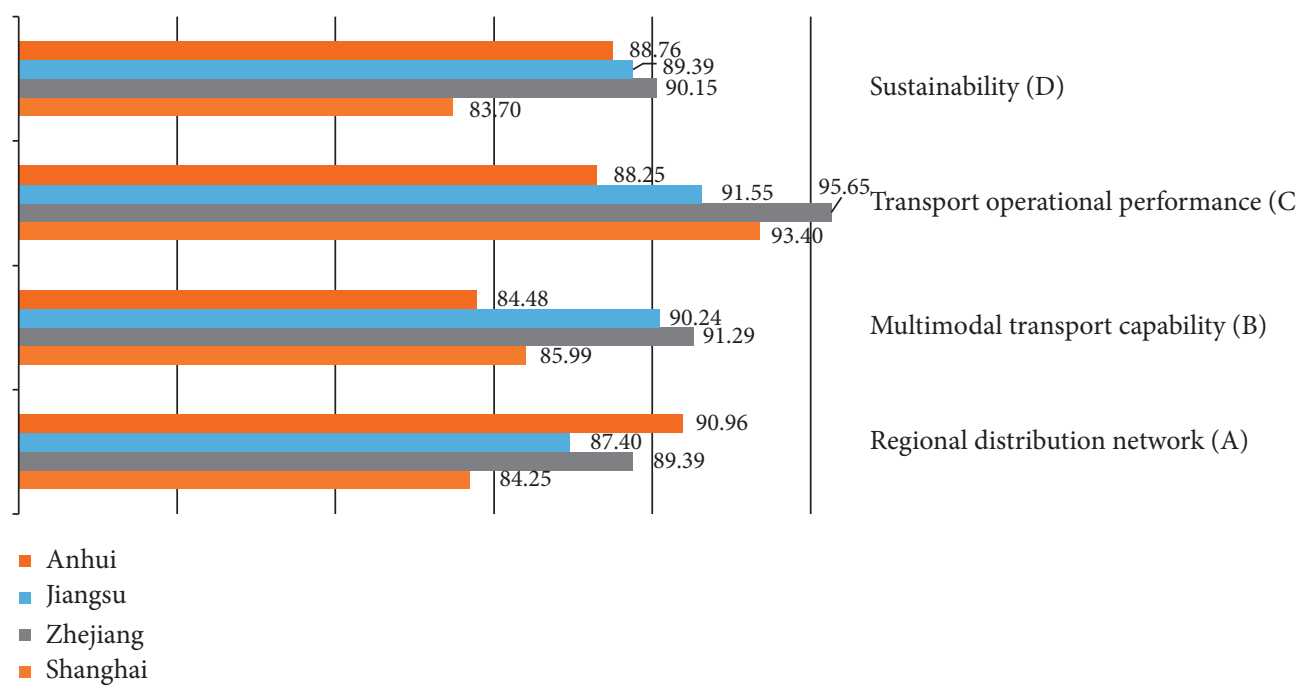

FIgURE 10: The score of the first-level indicators.

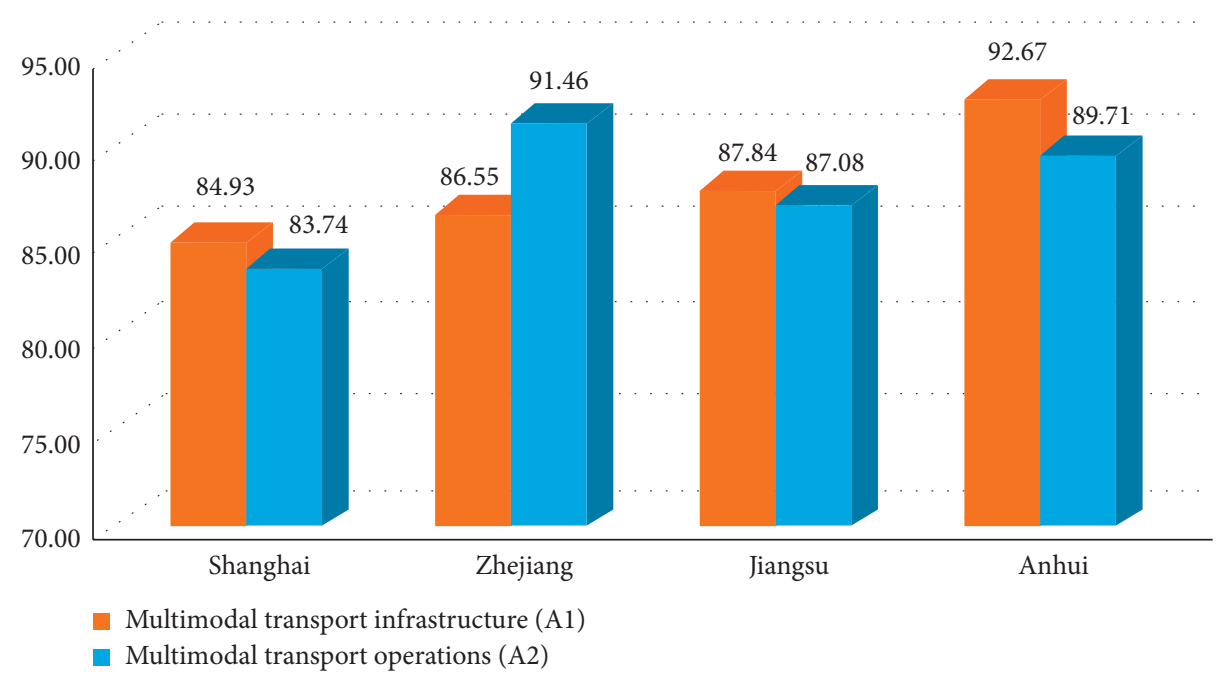

FIgURE 11: The index scores of the regional distribution network.

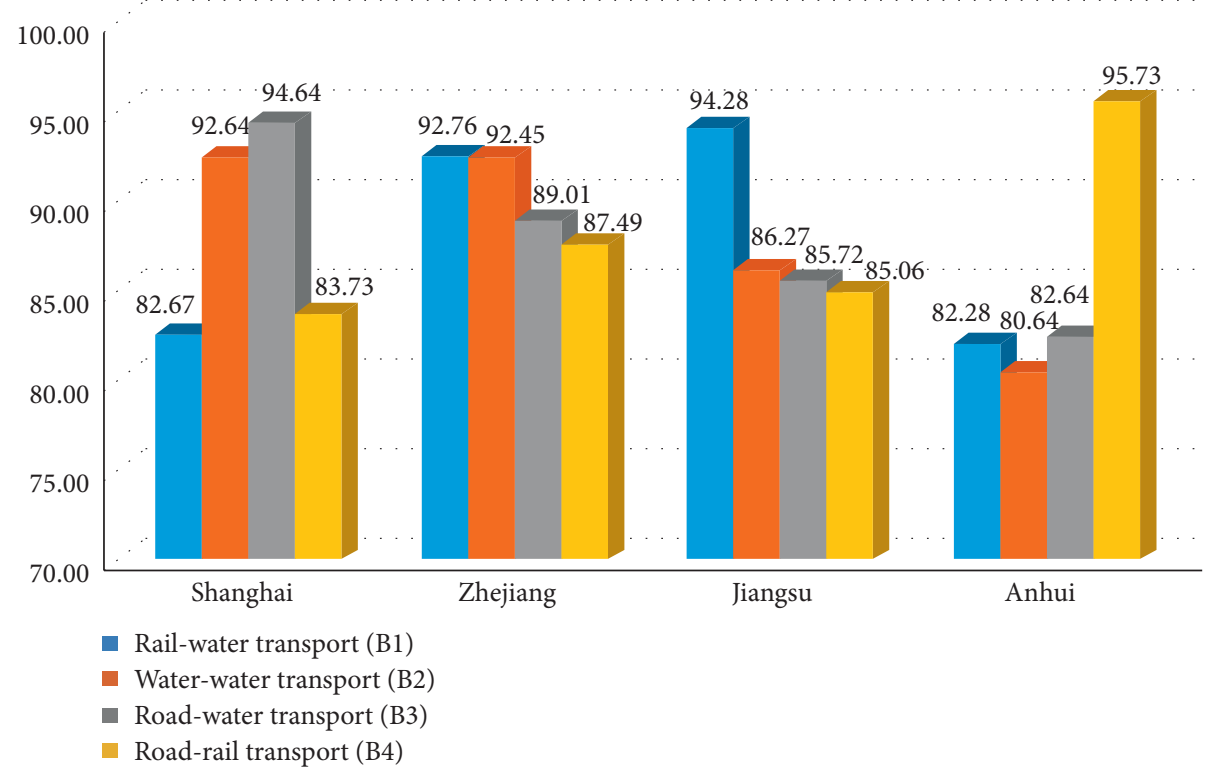

Figure 12: The scores of the multimodal transport capability. 


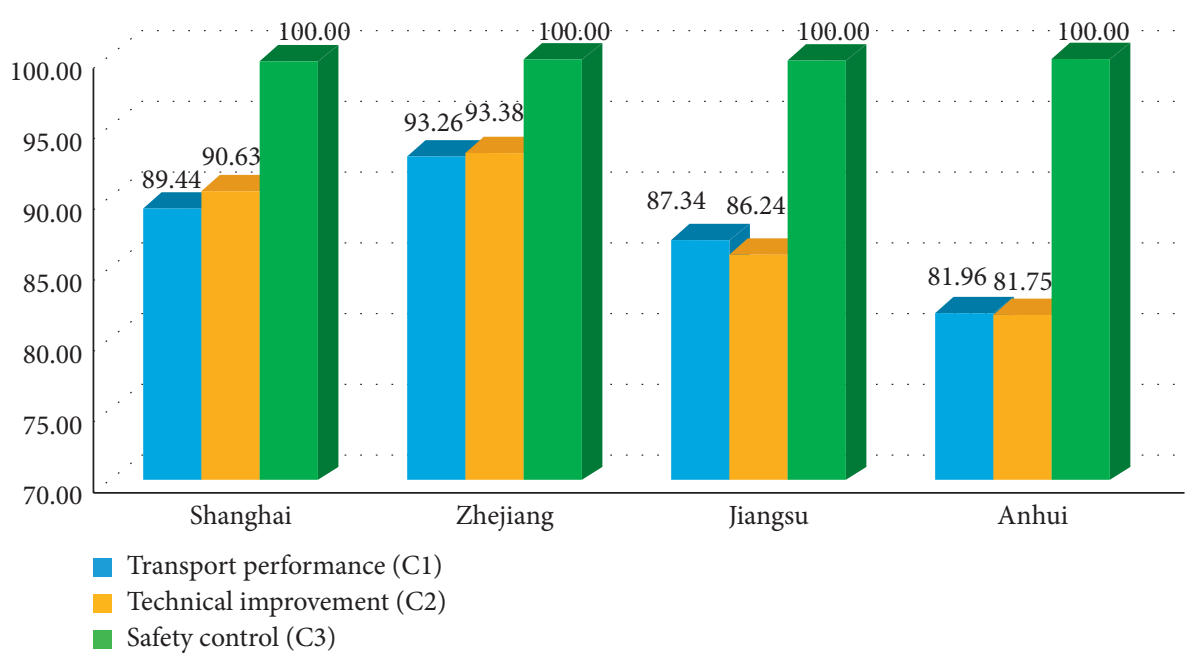

Figure 13: The scores of the transport operational performance.

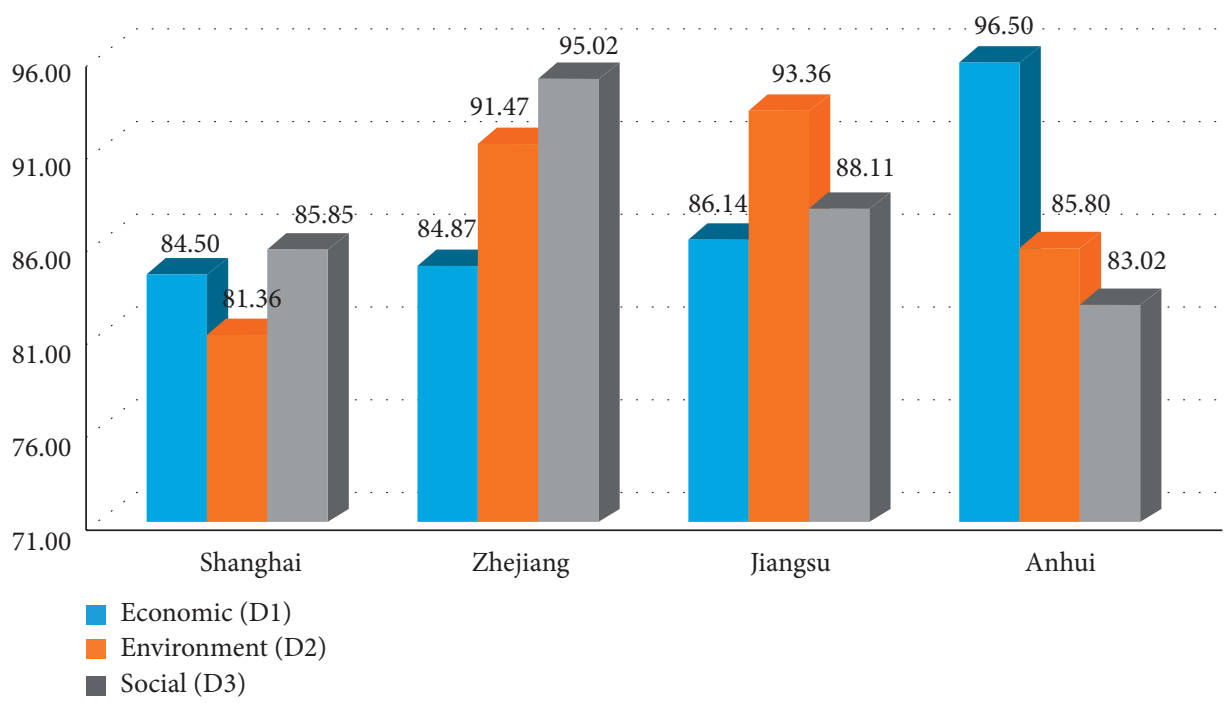

FIgURE 14: The scores of the sustainability.

\section{Conclusions}

This research proposes a method to evaluate the current status of the rail-based multimodal freight transport system in the Yangtze River Delta economics zone and reveals the impacts of HSR development on rail-based freight transport. Here are some major findings:

(1) The rail-based freight transport gradually plays a more important role in the multimodal transport in the Yangtze River Delta region due to the capacity releases of the conventional railway with the growth of the HSR network. The development of HSR has a positive impact on the rail-based freight and container traffic especially for the railway stations along the eight vertical and eight horizontal arteries. Therefore, the policymaker should pay more attention to optimizing the conventional railway schedules for arterial stations to improve freight transport.
(2) The original transport market and modals still determine the multimodal transport structures. Zhejiang has led the rail freight transport while Shanghai mainly leads the waterway freight transportation. Meanwhile, the road-rail transport in Anhui and water-rail transportation in Jiangsu are also well developing within the Yangtze River Delta region. Thus, the policymaker should design different incentives based on the original transport modals in each region to promote rail-based freight transport.

(3) Overall, the designed comprehensive index is shown to be efficient to evaluate multimodal transport, especially for rail-based freight transport. Currently, rail-based freight transport is still not competitive compared with road-based and water-based transport in the Yangtze River Delta region. However, the timely updates of this evaluation are important for the government to trace the development of rail- 
based multimodal transport and release more efficient policies.

Besides, the proposed evaluation method is also available for evaluating the development of rail-based multimodal transport for individual cities and logistic centers, which is also inspiring for developing rail-based freight transport in different levels.

\section{Data Availability}

No data were used to support this study.

\section{Conflicts of Interest}

The authors declare that they have no conflicts of interest.

\section{Acknowledgments}

This work was sponsored by the National Natural Science Foundation of China (grant nos. 72072112, 71602114, 71804108, and 72001135), Shanghai Rising-Star Program (grant no. 19QA1404200), and Shanghai Sailing Program (grant no. 20YF1416600).

\section{References}

[1] L. Zhen, Z. Liang, D. Zhuge, L. H. Lee, and E. P. Chew, "Daily berth planning in a tidal port with channel flow control," Transportation Research Part B: Methodological, vol. 106, pp. 193-217, 2017.

[2] C. M. Tan and J. L. He, "Integrated proactive and reactive strategies for sustainable berth allocation and quay crane assignment under uncertainty," Annals of Operations Research, 2021.

[3] J. He, Y. Wang, C. Tan, and H. Yu, "Modeling berth allocation and quay crane assignment considering QC driver cost and operating efficiency," Advanced Engineering Informatics, vol. 47, Article ID 101252, 2021.

[4] W. Ma, Q. Wang, H. Yang, G. Zhang, and Y. Zhang, "Understanding airline price dispersion in the presence of highspeed rail," Transport Policy, vol. 95, pp. 93-102, 2020.

[5] A. Zhang, Y. Wan, and H. Yang, "Impacts of high-speed rail on airlines, airports and regional economies: a survey of recent research," Transport Policy, vol. 81, pp. A1-A19, 2019.

[6] Z. Chen and K. E. Haynes, "Impact of high-speed rail on regional economic disparity in China," Journal of Transport Geography, vol. 65, pp. 80-91, 2017.

[7] F. Zhang, Z. Yang, J. Jiao, W. Liu, and W. Wu, "The effects of high-speed rail development on regional equity in China," Transportation Research Part A: Policy and Practice, vol. 141, pp. 180-202, 2020.

[8] F. Long, L. Zheng, and Z. Song, "High-speed rail and urban expansion: an empirical study using a time series of nighttime light satellite data in China," Journal of Transport Geography, vol. 72, pp. 106-118, 2018.

[9] Y. Liang, K. Zhou, X. Li, Z. Zhou, W. Sun, and J. Zeng, "Effectiveness of high-speed railway on regional economic growth for less developed areas," Journal of Transport Geography, vol. 82, Article ID 102621, 2020.

[10] H. Li, K. Wang, K. Yu, and A. Zhang, "Are conventional train passengers underserved after entry of high-speed rail?- evidence from Chinese intercity markets," Transport Policy, vol. 95, pp. 1-9, 2020.

[11] M. Diao, "Does growth follow the rail? The potential impact of high-speed rail on the economic geography of China," Transportation Research Part A: Policy and Practice, vol. 113, pp. 279-290, 2018.

[12] J. Cao, X. C. Liu, Y. Wang, and Q. Li, "Accessibility impacts of China's high-speed rail network," Journal of Transport Geography, vol. 28, pp. 12-21, 2013.

[13] F. Sun and Y. S. Mansury, "Economic impact of high-speed rail on household income in China," Transportation Research Record: Journal of the Transportation Research Board, vol. 2581, no. 1, pp. 71-78, 2016.

[14] M. Yin, L. Bertolini, and J. Duan, "The effects of the highspeed railway on urban development: international experience and potential implications for China," Progress in Planning, vol. 98, pp. 1-52, 2015.

[15] E. Cascetta, A. Cartenì, I. Henke, and F. Pagliara, "Economic growth, transport accessibility and regional equity impacts of high-speed railways in Italy: ten years ex post evaluation and future perspectives," Transportation Research Part A: Policy and Practice, vol. 139, pp. 412-428, 2020.

[16] Y. Chen, "High speed Rail and China's New Economic Geography: impact assessment from the regional science perspective," Eurasian Geography and Economics, Edward Elger, Cheltenham, UK, 2020.

[17] J. Weng, X. Zhu, and X. Li, "Impact of high-speed rail on destination accessibility: a case study of China," Journal of China Tourism Research, vol. 16, pp. 494-509, 2020.

[18] Z. Chen and K. E. Haynes, "Impact of high-speed rail on international tourism demand in China," Applied Economics Letters, vol. 22, no. 1, pp. 57-60, 2015.

[19] Z. Yang and T. Li, "Does high-speed rail boost urban tourism economy in China?," Current Issues in Tourism, vol. 23, no. 16, pp. 1973-1989, 2020.

[20] Z. Chen, Z. Wang, and H. Jiang, "Analyzing the heterogeneous impacts of high-speed rail entry on air travel in China: a hierarchical panel regression approach," Transportation Research Part A: Policy and Practice, vol. 127, pp. 86-98, 2019.

[21] Q. Zhang, H. Yang, and Q. Wang, "Impact of high-speed rail on China's Big Three airlines," Transportation Research Part A: Policy and Practice, vol. 98, pp. 77-85, 2017.

[22] Q. Zhang, H. Yang, Q. Wang, A. Zhang, and Y. Zhang, "Impact of high-speed rail on market concentration and Lerner index in China's airline market," Journal of Air Transport Management, vol. 83, Article ID 101755, 2020.

[23] H. Yang and A. Zhang, "Effects of high-speed rail and air transport competition on prices, profits and welfare," Transportation Research Part B: Methodological, vol. 46, no. 10, pp. 1322-1333, 2012.

[24] H. Yang, W. Ma, Q. Wang, K. Wang, and Y. Zhang, "Welfare implications for air passengers in China in the era of highspeed rail," Transport Policy, vol. 95, pp. A1-A13, 2020.

[25] C. Wu, M. Liao, Y. Zhang, M. Luo, and G. Zhang, "Network development of low-cost carriers in China's domestic market," Journal of Transport Geography, vol. 84, Article ID 102670, 2020.

[26] I. Watson, A. Ali, and A. Bayyati, "Freight transport using high-speed railways," International Journal of Transport Development and Integration, vol. 3, no. 2, pp. 103-116, 2019.

[27] J. A. Pazour, R. D. Meller, and L. M. Pohl, "A model to design a national high-speed rail network for freight distribution," Transportation Research Part A: Policy and Practice, vol. 44, no. 3, pp. 119-135, 2010. 
[28] Y. Li, Z. Chen, and P. Wang, "Impact of high-speed rail on urban economic efficiency in China," Transport Policy, vol. 97, pp. 220-231, 2020.

[29] E. Mu and M. Pereyra-Rojas, "Understanding the analytic hierarchy process," Practical Decision Making, pp. 7-22, Springer, Berlin, Germany, 2017.

[30] L. Zhen, "Tactical berth allocation under uncertainty," European Journal of Operational Research, vol. 247, no. 3, pp. 928-944, 2015. 